\title{
TRANSTORNO DO ESPECTRO AUTISTA (TEA) E TRANSTORNO DO DÉFICIT DE ATENÇÃO E HIPERATIVIDADE (TDAH): IMPLICAÇÕES GENÉTICAS E AMBIENTAIS, MULTIFATORIAIS
}

\section{REVISÃO INTEGRATIVA}

CORRÊA JÚNIOR, Jurandir De Sousa ${ }^{1}$

CORRÊA JÚNIOR, Jurandir De Sousa. Transtorno do espectro autista (TEA) e transtorno do déficit de atenção e hiperatividade (TDAH): implicações genéticas e ambientais, multifatoriais. Revista Científica Multidisciplinar Núcleo do Conhecimento. Ano 06, Ed. 06, Vol. 09, pp. 155-167. Junho de 2021. ISSN: 24480959 , Link de acesso:

\section{https://www.nucleodoconhecimento.com.br/psicologia/transtorno-do-deficit}

\section{RESUMO}

O presente trabalho aborda o tema Transtorno do Espectro Autista (TEA) e Transtorno do Déficit de Atenção e Hiperatividade (TDAH), psicopatologias do desenvolvimento. Muitas, são as lacunas existentes no que tange a etiologia complexa dos transtornos em observação. No entanto, ciências envolvidas, tais como, Genética, Neurologia, Psiquiatria, Psicologia, etc., não tem medido esforços no sentido de trazerem novos conhecimentos para o aludido contexto psicopatológico. Assim, tendo em vista a constante necessidade de atualizações que contribuam para o desenvolvimento da temática no âmbito das ciências promotoras de saúde, o estudo corrente, tem como principal objetivo, empreender uma revisão etiológica das possíveis implicações genéticas e ambientais, presentes nas ocorrências de tais transtornos, bem como

\footnotetext{
${ }^{1}$ Pós-Graduação Lato Senso Em Antropologia E Música. Graduação Em História E Música. Graduação Em Andamento Em Psicologia.
}

RC: 88702

Disponível em: https://www.nucleodoconhecimento.com.br/psicologia/transtorno-do-deficit 
referência às causas multifatoriais. Para tanto, a pesquisa foi realizada por meio de levantamento bibliográfico documental, proveniente de literaturas específicas da última década. Sobre o Autismo, os resultados do estudo indicam para a etiologia gene-ambiental e a relevância multifatorial. Todavia, os estudos genéticos no campo do TEA, ainda são limitados, devido à complexidade desta psicopatologia do desenvolvimento, tendo muito que alcançar. Por outro lado, no campo do TDAH, há expressiva influência neurogenética participante nas possibilidades etiológicas do referido transtorno. Contudo, neste caso, a participação da causalidade multifatorial é uma constante.

Palavras-Chave: Transtorno do Espectro Autista (TEA), Transtorno do Déficit de Atenção e Hiperatividade (TDAH), Psicopatologias do Desenvolvimento, Implicações Genéticas e Ambientais, Multifatoriais.

\section{INTRODUÇÃO}

O Autismo, ou como é conhecido cientificamente por Transtorno do Espectro Autista (TEA), bem como o Transtorno do Déficit de Atenção e Hiperatividade (TDAH), são psicopatologias do desenvolvimento que acarretam uma ampla gama de desordens neurológicas, psíquicas com efeitos comportamentais e sociais. Diversos, são os fatores que se inter-relacionam para motivar o aparecimento de tais transtornos, que podem ser genéticos, ambientais com relevância multifatorial. Além disso, as psicopatologias em referência, não raramente, agem em comorbidade com outros problemas psicopatológicos que se envolvem no quadro clínico-patológico dos indivíduos afetados.

No Autismo, os estudos na área de genética, têm colaborado com avanços na pesquisa pela busca de envolvimento de genes como fatores de riscos ao problema. Ademais, alguns mapeamentos de anormalidades cromossômicas conhecidas correlacionadas ao TEA são possíveis. No entanto, tais avanços ainda são limitados,

RC: 88702

Disponível em: https://www.nucleodoconhecimento.com.br/psicologia/transtorno-do-deficit 
devido à complexidade desta psicopatologia que, também, apresenta causalidades ambientais, multifatoriais.

No TDAH, influências neurogenéticas são importantes, indicando quadros de herdabilidades que costumam aparecer na infância, geralmente perdurando por toda a vida do indivíduo. Todavia, nesse contexto, não há determinação genética, mas, predisposições que contribuem no processo etiológico da psicopatologia; apresentando, com efeito, o fator multifatorial/multifuncional.

Assim, consoante à complexidade etiológica de tais transtornos, o problema que norteou a construção deste artigo consistiu no seguinte enfoque: que possibilidades de implicações multifatoriais podem estar imbricadas no espectro clínico do TEA e do TDAH? Portanto, é relevante fazermos uma breve incursão no campo das psicopatologias do desenvolvimento em questão, com o objetivo de revisar peculiaridades de cada uma, assim como as prováveis implicações genéticas, ambientais, multifatoriais; visando, igualmente, a busca por atualizações nessa esfera de conhecimento, a fim de contribuir com o avanço do âmbito científico na promoção de saúde.

Por fim, no tocante aos procedimentos investigativos, pretendemos optar pelo levantamento bibliográfico de literaturas do último decênio, haja vista, o caráter emergente da ciência. Uma das razões para a escolha desse tipo de delineamento consiste na possibilidade de articulações que se exigem na relação entre a fundamentação teórica em consideração ao objeto a ser pesquisado. Além disso, quanto ao objetivo fundamental, a pesquisa foi do tipo, exploratória, pois visa ao descobrimento de noções e insights referentes à temática em estudo.

\section{O AUTISMO: VARIANTES GENÉTICAS E AMBIENTAIS, MULTIFATORIAIS}

O Autismo, identificado tecnicamente como Transtorno do Espectro Autista (TEA), é uma psicopatologia do desenvolvimento que compromete três importantes áreas do RC: 88702

Disponível em: https://www.nucleodoconhecimento.com.br/psicologia/transtorno-do-deficit 
amadurecimento humano: comunicação, socialização e comportamento. "Antigamente achava-se que o autismo era uma versão infantil da esquizofrenia, mas agora se sabe que é um transtorno distinto, marcado por anormalidades nas relações sociais, déficits de comunicação e interesses restritos" (PLOMIN et al, 2011, p. 217).

O transtorno em destaque possui muitos subtipos, que se manifestam de maneira singular em cada indivíduo. Pelo fato de ser abrangente, quanto aos níveis de comprometimento, é usual a expressão espectro. O Autismo, geralmente, atua em comorbidade com outros transtornos psicopatológicos e condições de saúde diversas. Desordens como, depressão, Síndrome de Asperger, Síndrome de Tourette, Síndrome de Down, hipotireoidismo, hipertensão, podem estar associadas ao TEA. Ainda complementando, "[...] outras condições do neurodesenvolvimento como Deficiência Intelectual (DI), Transtorno Obsessivo Compulsivo (TOC), Transtorno de Déficit da Atenção e Hiperatividade (TDAH) e algumas condições psiquiátricas como esquizofrenia, [...] e transtorno do humor e afeto [...]" (PIGNATARI, 2019, p. 2), podem, também, se associarem ao quadro psicopatológico do Autismo.

É importante exemplificar alguns sinais/comportamentos relacionados ao paciente autista: 1) Não imitar; 2) Não compartilhar seus interesses e atenção, apontando para algo ou não olhar quando apontamos algo; 3) Não manter contato visual por mais de dois segundos; 4) Isolar-se ou não se interessar por outras crianças; 5) Não atender quando chamado pelo nome; 6) Fazer movimentos repetitivos sem função aparente; 7) Interesse restrito ou hiperfoco; 8) Repetir frases ou palavras em momentos inadequados, sem a devida função (ecolalia); 9) Olhar com o canto do olho quando se sente desconfortável; 10) Ser muito preso a rotinas a ponto de entrar em crise, entre outros (PAIVA JUNIOR, 2020).

No que diz respeito à etiologia (estudo ou ciência das causas) do Autismo, muitas são as variáveis que interagem para desencadear o problema. Fatores de riscos genéticos e ambientais se combinam, comumente, para a síntese do transtorno. Entretanto, devido às complexas associações, multiplicidade de sintomas que se manifestam de

$\mathrm{RC}: 88702$

Disponível em: https://www.nucleodoconhecimento.com.br/psicologia/transtorno-do-deficit 
forma singular em cada pessoa, determinar a causa exata do TEA, torna-se tarefa difícil.

Não obstante,

a pesquisa genética começou a ser aplicada aos transtornos que aparecem na infância. Uma das maiores surpresas a partir da pesquisa em genética do comportamento envolve o autismo, que era considerado como ambiental na sua origem, mas apresentou estimativas de herdabilidade maiores do que $90 \%$. Embora os três componentes dos diagnósticos tradicionais dos TEAS (problemas com a interação social, déficits na comunicação e interesses restritos) sejam altamente herdáveis, é cada vez maior a evidência genética multivariada de que eles diferem geneticamente. A alta herdabilidade dos TEAS levou a uma série de estudos de associação de mais de 100 genes candidatos, mas ainda não foi encontrado nenhum gene ou associação consistente [...] (PLOMIN et al, 2011, p. 220, grifo nosso).

Todavia, vejamos o que a doutora em biologia molecular e pesquisadora, Graciela Pignatari, têm a nos dizer sobre como a ciência explica hoje a ligação entre autismo e genética (título de seu artigo). Em termos mais recentes,

os avanços tecnológicos foram importantíssimos para a evolução do conhecimento e a identificação de genes relacionados à etiologia do TEA. De acordo com informações obtidas em fevereiro de 2019, no site da Simons Foundation (SFARI genes), 1054 genes foram relacionados com o autismo. [Por conseguinte], [...] uma única alteração genética é suficiente para causar o TEA, mas na maioria dos casos não ocorrem apenas devido a alterações em um único gene, pelo contrário, elas envolvem distúrbios moleculares complexos em múltiplos genes importantes para os processos biológicos, como também em genes que controlam, durante o neurodesenvolvimento, a expressão gênica. [Ainda acrescentando], [...] apesar dos estudos científicos evidenciarem que no autismo a herdabilidade é estimada entre 70 a $90 \%$ (conforme estudos de 2014 e 2017), o diagnóstico do Transtorno do Espectro do Autismo (TEA) é baseado em exame clínico, realizado por neuropediatras ou psiquiatras, seguindo as considerações da $5^{\underline{a}}$ edição do Manual Diagnóstico e Estatístico de Transtornos Mentais (DSM-5) (PIGNATARI, 2019, p. 1-2).

Portanto, existem muitos genes identificados que são suscetíveis à interação com variantes ambientais. Nesse contexto, a exposição a agentes do ambiente, tais como

RC: 88702

Disponível em: https://www.nucleodoconhecimento.com.br/psicologia/transtorno-do-deficit 
agentes químicos ou infecciosos (abrangendo toxinas ambientais e medicamentações), no decorrer da gestação, pode causar o Autismo (MANDAL, 2019). Fica então, evidente, que tais influências gênicas interagem com a ambiência em vários graus. Por um lado, motivando sintomatologias específicas, por outro, atuando na severidade dos sintomas da psicopatologia.

HOXA1, da herança recessivo-autossomal é somente um de muitos genes envolvidos no espectro de desordens do autismo. Pode haver uma participação do gene de DbetaH (DBH) também. [Crianças com Síndrome de Down e Síndrome do X Frágil, associadas ao TEA podem ter] [...] um baixo nível do B-hydroxylase da dopamina do soro, que catalisa a conversão da dopamina à noradrenalina. Outros genes suspeitados incluem NLGN3, NLGN4, NRXN1, MeCP2 etc. O gene do $X$ frágil é associado com as desordens do autismo e há uma associação positiva do gene FMR-1 com autismo. As mutações ou as mudanças no gene synaptic do andaime SHANK2 foram documentadas no autismo. Além, o gene de Reelin foi associado com o TEA. Este gene ajuda na laminação do cérebro durante a vida fetal e ajuda na pilha que sinaliza na vida adulta (MANDAL, 2019, p. 2).

Vale informar, que estudos sistematizados com gêmeos, a partir de 1977, foram importantes para diagnósticos mais precisos no campo do TEA; trazendo em cena, paulatinamente, a relevância da participação genética no espectro de atuação do Autismo. Entretanto, anteriormente, se pensava que tal psicopatologia era fundamentalmente ambiental, porém,

[...] a partir dos estudos com gêmeos e, com a família, a visão em relação ao autismo mudou drasticamente. Em vez de ser visto como um transtorno com causas ambientais, ele é agora considerado como um dos transtornos mentais mais herdáveis (FREITAG, 2007 apud PLOMIN et al, 2011, p. 218).

Voltando à questão das especificações gênicas, associadas ao Transtorno do Espectro Autista, é importante ilustrar um quadro com informações reveladoras de alterações cromossômicas conhecidas relacionadas com o Autismo. O mesmo, lista diversas síndromes em relação com o TEA, bem como nos traz dados sobre o fenômeno das deleções, duplicações nas estruturas de cromossomos, além de informar, genes com suas respectivas regiões de alteração cromossômica. Isto vem 
reforçar, o fator genético de comorbidade entre o Autismo e outras psicopatologias do desenvolvimento.

Quadro 1 - Anormalidades cromossômicas conhecidas associadas com autismo.

\begin{tabular}{|c|c|c|}
\hline & GENE/REGÃO CROMOSSÔMICA & PREVALÊNCIA \\
\hline Síndrome da delecãa lq21 & lg21 del & desconhecido \\
\hline Sindrome da duplicacão lq21 & $1921 d u p$ & desconhecido \\
\hline Sindrome da delecão 2037 & $2937 \mathrm{del}$ & desconhecido \\
\hline Sindrome da duplicacão da região Williams- & $7 q 11.23$ dup & $1 / 12.500-1 / 20.000$ \\
\hline \multicolumn{3}{|l|}{ Sindromes do cromossomo $15 \mathrm{~g}$} \\
\hline Sindrome de Angelman & del/mut no UBE3A matemo & $1 / 10.000-1 / 12.000$ \\
\hline Sindrome de Prader-Willi & del no alelo paterno em & $1 / 10.000-1 / 15.000$ \\
\hline 15 q isodicêntrico & dup 15q11-a13, GABRB3 & $1 / 30.000$ \\
\hline Hipomelanose de Ito & del mosaico 15g11-q13 & $1 / 10.000$ \\
\hline Sindrome Smith-Magenesis & $17 \mathrm{pl1.2 \textrm {del }}$ & $1 / 15.000$ \\
\hline Síndrome Potocki-Lupsky & $17 p 11.2 \mathrm{dup}$ & desconhecido \\
\hline Sindrome de Down & Trissomia do crom. 21 & $1 / 1.000$ \\
\hline Síndrome VelocardiofacialDi George & $22 \mathrm{~g} 11.2 \mathrm{del}$ & $1 / 4.000$ \\
\hline Sindrome da duplicacão 22q11 & 22 gl1.2dup & desconhecido \\
\hline Sindrome Phelan-McDermid & $22 q 13.3 \mathrm{del}$ & Desconhecido \\
\hline
\end{tabular}

Fonte: (ZANOLLA et al, 2015, p. 32).

Outrossim, o Transtorno do Espectro Autista (TEA) apresenta-se como um promissor exemplo com potencialidades de demonstração da genética do neurodesenvolvimento e sua respectiva complexidade. Porquanto, seu amplo espectro clínico está fundamentado em aspectos genéticos multifários e enigmáticos, passíveis de serem herdados ou não. Ademais, é possível verificar que as chamadas formas não sindrômicas possuem uma herança do tipo multifatorial concatenada

RC: 88702

Disponível em: https://www.nucleodoconhecimento.com.br/psicologia/transtorno-do-deficit 
a variantes e/ou agravantes genéticos e ambientais, numa conjuntura combinativa com características aditivas - conforme estudo realizado em 2018 (PIGNATARI, 2019, grifo nosso).

Figura 1 - Modelo de copo.
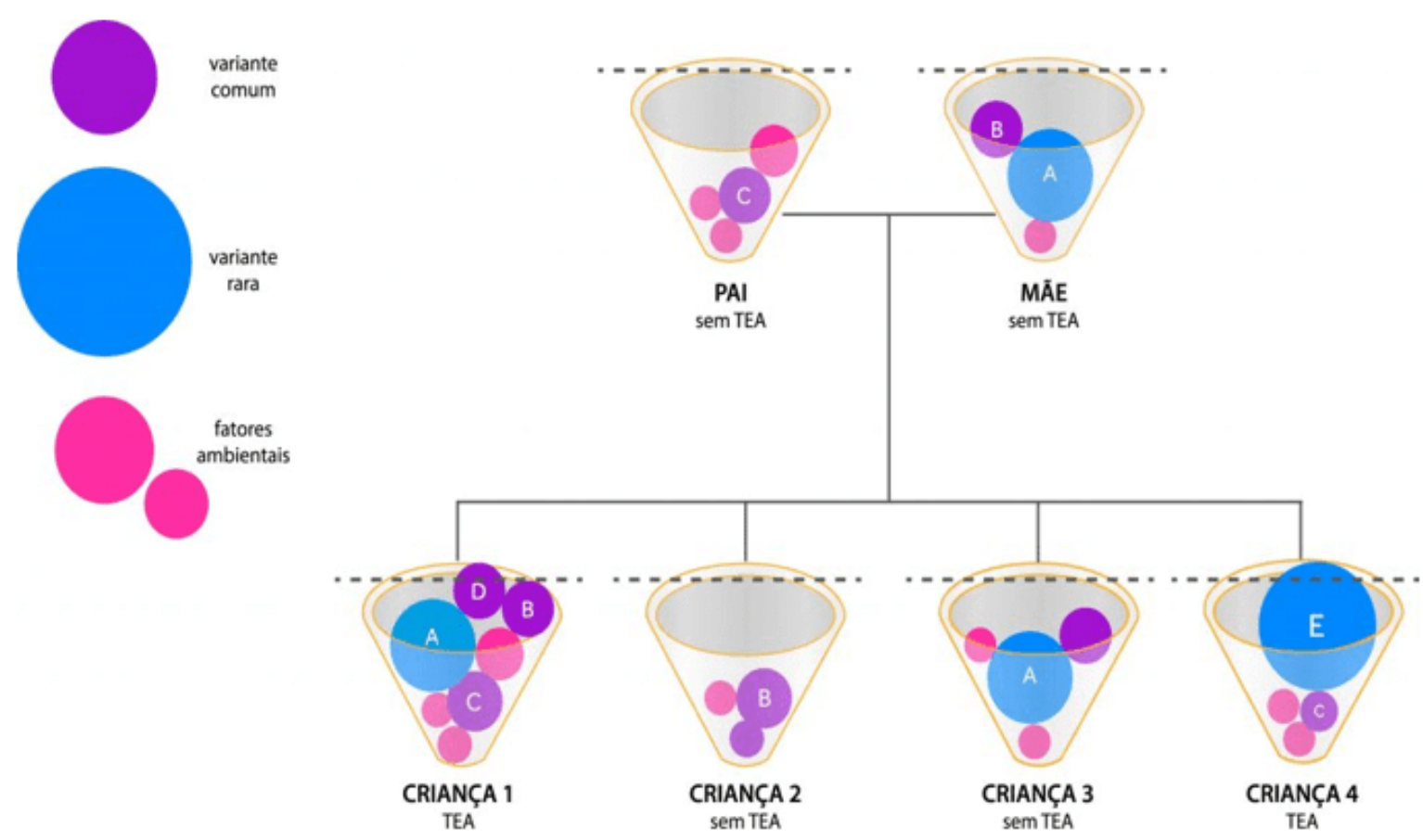

Fonte: (PIGNATARI, 2019, p.2).

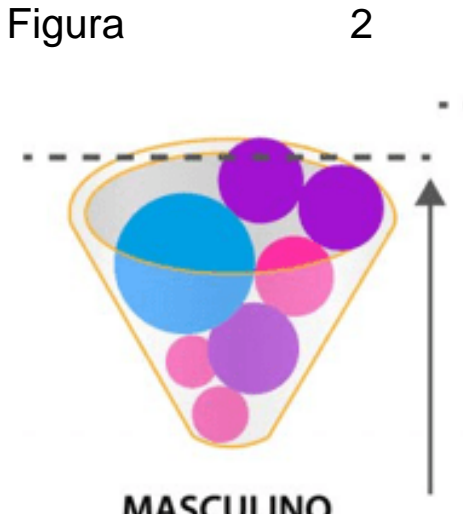

MASCULINO

TEA

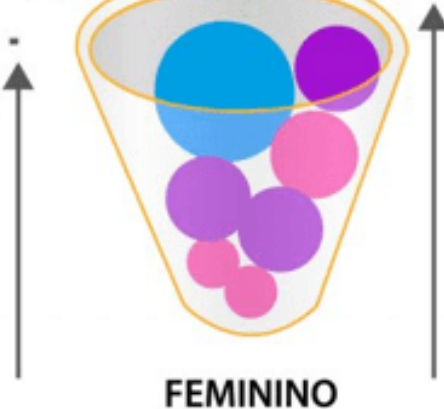

sem TEA
Modelo

de

copo.

Fonte: (Id., 2019, p. 3).

RC: 88702

Disponível em: https://www.nucleodoconhecimento.com.br/psicologia/transtorno-do-deficit 
Vejamos a explicação do aludido modelo de copo, como modelo de herança e limiar multifatorial, ilustrado nas figuras 1 e 2 acima expressas, nas palavras da mesma autora.

O modelo genético que explica o TEA foi chamado de modelo de copo e é um modelo de herança e limiar multifatorial que apresenta os impactos das variantes genéticas e ambientais com maior ou menor risco associado ao TEA, representados por círculos de tamanhos diferentes, e a borda do copo representa o limite. Observe que indivíduos que ultrapassam esse limite estão no TEA (Figura 1). No modelo de copo, os indivíduos do sexo masculino são representados por copos de tamanho menor, em relação ao sexo feminino, demonstrando uma diferença para atingir o limiar de diagnóstico (Figura 2). Estudos científicos mostraram que mulheres com TEA tem um número muito maior de variantes genéticas associadas ao transtorno se comparadas a homens com TEA, sugerindo que indivíduos do sexo feminino são mais resistentes a tais mutações o que explicaria a proporção de 4 meninos para 1 menina, conforme estudo de 2014. [Assim], devemos ter em mente que o TEA é uma condição multigênica e multifatorial com combinação de variantes genéticas raras e comuns, que podem ou não ser herdadas. [...] [Portanto], além dos fatores genéticos, fatores ambientais corroboram com esse transtorno. [Ademais], a idade paterna e o uso de ácido valpróico são dois fatores de risco importantes e comprovados. Já a idade materna, desnutrição e alimentação na infância, baixo peso no nascimento ainda precisam ser mais bem estudados, embora já sejam considerados como fatores de risco [...]. [...] Por fim, vale ressaltar que o conhecimento genético dos indivíduos com TEA está alterando gradualmente o conselho científico e clínico e pode ser mais útil que apenas ser utilizado para diferenciar TEA sindrômicos e não-sindrômicos (PIGNATARI, 2019, p. 1 - 6, grifo nosso).

Em última análise, o Transtorno do Espectro Autista se configura como uma das psicopatologias do desenvolvimento mais complexa e de estudo etiológico difícil; apresentando, também, caráter sindrômico e não-sindrômico, e/ou ainda, alto grau de comorbidade. 


\section{O TRANSTORNO DO DÉFICIT DE ATENÇÃO E HIPERATIVIDADE (TDAH): ETIOLOGIA POSSÍVEL?}

O Transtorno do Déficit de Atenção e Hiperatividade (TDAH) configura-se também, como uma psicopatologia do desenvolvimento. Sua sintomatologia gira em torno de marcantes características como, desatenção, agitação e impulsividade. Este distúrbio pode ser dividido em três categorias: desatento, hiperativo impulsivo e combinado, todos com seus traços peculiares. O TDAH é uma desordem de significativa influência neurogenética, apresentando aditivamente, implicação multifatorial/multifuncional. Geralmente, surge na infância, persistindo comumente na vida adulta, tendo maior incidência no sexo masculino (SCHMIDEK et al, 2018 apud PIDDE et al, 2018).

Quanto aos tipos do TDAH, em linhas gerais, três categorias são possíveis, como vimos. A primeira faz referência à desatenção. $O$ desatento possui dificuldade em seguir e cumprir instruções. Comumente, incorre em erros por falta de atenção, cuidado, não enxergando detalhes, bem como parecendo não ouvir. O segundo reflete o hiperativo impulsivo, que apresenta inabilidade em controlar seus comportamentos irrequietos. Ou seja, corre sem sentido, dispõe de dificuldade em ficar/permanecer sentado, mexe inquietamente os pés e as mãos, não consegue concentração em atividades silenciosas. $O$ terceiro indica o combinado, categoria caracterizada pela associação dos tipos desatento e hiperativo impulsivo (MAIA; CONFORTIN, 2015 apud PIDDE et al, 2018, grifo nosso).

Como o TEA, o TDAH, não raro, age em comorbidade com outros transtornos durante o ciclo da vida. Alguns destes são: transtorno de conduta, transtorno desafiador opositor, transtorno de humor bipolar, dificuldades no processo de aprendizagem, transtorno de personalidade antissocial, desordens provenientes de abuso de elementos psicoativos e transtorno de tiques. Aliás, o TDAH apresenta-se também, confundido com distintos transtornos através de mimetismo sintomatológico, ou seja, reproduz/imita um sintoma de outra desordem psicopatológica.

$\mathrm{RC}: 88702$

Disponível em: https://www.nucleodoconhecimento.com.br/psicologia/transtorno-do-deficit 
Por conseguinte, quanto à etiologia do Transtorno do Déficit de Atenção e Hiperatividade, constatamos que o TDAH consiste na conjunção de fatores diversos que abrangem aspectos sociais, culturais, genéticos, alterações na dinâmica de funcionamento cerebral e/ou em sua estrutura. Desse modo, questões socioambientais como família numerosa, baixa classe social, incidência de violência e criminalidade dos pais, disfunção familiar apresentando graves desentendimentos, exposição a práticas tabagistas e consumo de álcool no período gestacional, além de diversas outras ocorrências durante a gravidez, como eclampsia, toxemia, estresse fetal, tempo demasiado de duração do parto, baixo peso ao nascer e saúde materna precária estão associadas nas possíveis eventualidades causais do referido distúrbio (CASTRO; LIMA, 2018 apud PIDDE et al, 2018).

Sintetizando, "a etiologia do transtorno é multifatorial, ou seja, enquanto fenótipo o TDAH resulta da interação de vários fatores ambientais e genéticos que atuam na manifestação de seus diversos quadros clínicos" (ROMAN et al, 2003 apud COUTO; MELO-JUNIOR; GOMES, 2010, p. 243, grifo nosso).

Quanto ao aspecto etiológico genético, pesquisas epidemiológicas atestam reincidência familiar. Nesse caso, a recorrência do TDAH entre o grau de parentesco (pais e irmãos) é aproximadamente cinco vezes maior que a predominância na população. Tais informações foram alcançadas a partir de estudos de famílias com filhos gêmeos ou adotados (COUTO; MELO-JUNIOR; GOMES, 2010).

É pertinente salientar que, embora havendo pesquisas que constatem contribuição genética expressiva para a eventualidade do TDAH, não houve evidências de nenhum gene necessário ou determinante para a evolução do transtorno, isto, devido ao complexo quadro clínico do problema. No entanto, "[...] trabalhos recentes encontram evidências de que o TDAH se trata de um distúrbio neurobiológico. [Devido] [...] ao déficit funcional do lobo frontal, mais precisamente o córtex cerebral e ao déficit funcional de certos neurotransmissores" (SEGENREICH; MATTOS, 2007 apud COUTO; MELO-JUNIOR; GOMES, 2010, p. 243).

RC: 88702

Disponível em: https://www.nucleodoconhecimento.com.br/psicologia/transtorno-do-deficit 
Mesmo assim, investigações genéticas apontam que genes específicos com predisposição ao transtorno em referência, "[...] codificam sistemas de sinais de catecolaminas e incluem o transportador de dopamina (DAT), transportador de noradrenalina (NET), receptores dopaminérgicos D4 e D5, dopamina b-hidroxilase e a proteína-25 (SNAP-25) que facilitam a liberação dos neurotransmissores implicados no TDAH" (YANG et al, 2004; FARAONE et al, 2005 apud COUTO; MELO-JUNIOR; GOMES, 2010, p. 244).

Ademais, as perspectivas de averiguações científicas mais recentes, no que tange aos estudos de genética molecular no TDAH, convergem para pesquisas voltadas para as

[...] sequências genéticas envolvidas no funcionamento dos sistemas dopaminérgicos e noradrenérgicos como possíveis fatores desencadeadores dos fenômenos patofisiológicos do transtorno. Contudo, [tais estudos] [...] ainda são muito controversos, principalmente quanto ao papel dos genes DRD4 e DAT1, primeiros genes diretamente relacionados ao TDAH (COUTO; MELO-JUNIOR; GOMES, 2010, p. 249).

Em suma, com efeito, muitos fatores se inter-relacionam etiologicamente para desencadear o Transtorno do Déficit de Atenção e Hiperatividade, demonstrando, igualmente, uma realidade complexa na tarefa de diagnosticar os variados quadros clínicos do problema. Portanto, corroboramos que a etiologia do TDAH é, fundamentalmente, neuro-genético-ambiental/multifatorial.

\section{CONSIDERAÇÕES FINAIS}

Esta breve incursão investigativa no campo de estudos do Transtorno do Espectro Autista (TEA), bem como do Transtorno do Déficit de Atenção e Hiperatividade (TDAH), nos trouxe oportunidades de revisar aspectos peculiares de tais psicopatologias do desenvolvimento e suas etiologias. A pesquisa foi possível a partir de levantamento bibliográfico de literaturas científicas publicadas na última década. Leituras atentas foram realizadas com a finalidade de analisar, compreender e sintetizar as informações obtidas a respeito dos problemas psicopatológicos em RC: 88702

Disponível em: https://www.nucleodoconhecimento.com.br/psicologia/transtorno-do-deficit 
questão; objetivando, igualmente, trazer ao leitor um texto coeso, íntegro, porém, sucinto quanto às possibilidades de pesquisas.

Todavia, este trabalho não visa esgotar o assunto. Pelo contrário, a partir de lacunas existentes, propõe aos leitores pesquisadores, o aprofundamento em âmbitos como a área genética, campo de investigação até agora emergente na busca por melhor compreensão da complexidade clínica destes transtornos.

O TEA, apesar dos avanços no campo da genética, ainda nos apresenta uma etiologia multifatorial, ou seja, fatores genéticos e ambientais de complexa inter-relação dão o tom etiológico da referida psicopatologia. Aliás, o alto grau de comorbidade com outros transtornos, torna o Autismo uma espécie de convidativo plano fértil para novas pesquisas. Afinal, muito falta a ser elucidado.

O TDAH, mesmo possuindo expressiva influência neurogenética, também demonstra uma causalidade multifatorial. Isto, devido às complexidades diversas apresentadas pelo transtorno, além das comorbidades, como no TEA. Ademais, os estudos genéticos neste campo continuam limitados. Aqui, da mesma forma, o caminho a ser trilhado para entendimentos mais precisos sobre tal distúrbio, ainda é longo.

Enfim, a Genética do Comportamento, assim como ciências afins, parecem ter pela frente uma árdua tarefa a fazer: continuar a busca por decifrar o enigma da natureza do comportamento humano. Natureza esta que transcende a academia e a própria ciência, mas que permite a dúvida, oportunizando a eternização do ser cartesiano presente em cada um de nós, evocando, portanto, os atributos do duvidar, do pensar e do existir.

\section{REFERÊNCIAS}

COUTO, Taciana de Souza; MELO-JUNIOR, Mario Ribeiro de; GOMES, Cláudia Roberta de Araújo. Aspectos neurobiológicos do transtorno do déficit de atenção e hiperatividade (TDAH): uma revisão. Ciências \& Cognição, v. 15, n. 1, p. $241-251$,

$\mathrm{RC}: 88702$

Disponível em: https://www.nucleodoconhecimento.com.br/psicologia/transtorno-do-deficit 
abril de 2010. Disponível em <http://www.cienciasecognicao.org>. Acesso em 10 janeiro de 2021.

MANDAL, Ananya. Causas do autismo. p. 1-5, 30 de abril de 2019. Disponível em $<$ https://www.news-medical.net/health/Austism-Causes-(Portuguese).aspx>. Acesso em 11 de janeiro de 2021.

PAIVA JUNIOR, Francisco. O que é autismo? Revista Autismo. n. 8, p. 8 - 15, março de 2020. Disponível em <https://www.revistaautismo.com.br/o-que-e-autismo/>. Acesso em 12 de janeiro de 2021.

PIDDE, Áurea Gomes et al. O desafio do diagnóstico de TDAH e suas implicações. III CIPEEX - Ciência para a redução das desigualdades, v. 2, p. 942 - 947, dezembro de 2018.

Disponível

em

$<$ http://anais.unievangelica.edu.br/index.php/CIPEEX/article/view/2996>. Acesso em 10 de janeiro de 2021.

PIGNATARI, Graciela. Como a ciência explica hoje a ligação entre autismo e genética. Autismo x genética. p. 1 - 6, 28 de março de 2019. Disponível em $<$ https://www.revistaautismo.com.br/artigos/autismo-x-genetica/>. Acesso em 12 de janeiro de 2021.

PLOMIN, Robert et al. Genética do comportamento. $5^{\mathrm{a}}$ ed. Porto Alegre: Artmed, 2011.

ZANOLLA, Thais Arbocese et al. Causas genéticas, epigenéticas e ambientais do transtorno do espectro autista. TEA: causas genéticas, epigenéticas e ambientais. Universidade Presbiteriana Mackenzie. CCBS - Programa de Pós-Graduação em Distúrbios do Desenvolvimento. Cadernos de Pós-Graduação em Distúrbios do Desenvolvimento, São Paulo, v. 15, n. 2, p. 29 - 42, 2015.

Enviado: Março, 2021.

RC: 88702

Disponível em: https://www.nucleodoconhecimento.com.br/psicologia/transtorno-do-deficit 
Aprovado: Junho, 2021. 